\title{
Performance Evaluation of a Newly Designed Robotized Gearbox for Electric City Buses
}

\author{
K. GOKCE \\ Otokar Automotive and Defense Ind., Research and Development Department, 54580 Sakarya, Turkey, \\ E-mail:kgokce@otokar.com.tr

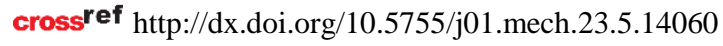

\section{Introduction}

The buses used in public transportation have had a big share in creating environmental pollution in metropolitan cities. Because of this fact, electric transportation is getting more and more popular nowadays in terms of environmental concerns. Battery powered electric buses are the most efficient and promising clean transportation choice for the cities as they can significantly help in cutting fuel consumption and emissions in city driving conditions.

The transmission system plays a critical role in electric vehicles for driving comfort, drivability, energy consumption and dynamic performance. Today, the studies [1-3] revealed that most of the battery electric vehicles (BEV) use single speed transmission (fixed ratio gearbox) which is very light, smooth and easy to adopt. However, these applications may require special electric motors with high torque capacity in a wide speed range in order to meet the high torque demand during acceleration and climbing events.

Recently, automated manual transmission (AMT) has gained widespread attention due to its high efficiency and reliability [4]. Multi-speed AMTs can provide high torque at low speeds and meet the maximum speed requirement with a moderate electric motor. There have been some examples of applying multi-speed AMT to electric buses [5]. In [6], a three-gear AMT was developed for an electric bus but the results (i.e. $1.86 \mathrm{~s}$ mean shift time and $\pm 35 \mathrm{~m} / \mathrm{s}^{3}$ shift jerk) were not satisfactory because of the time lag due to the stroke of the clutch. A similar study was also carried out on an electric bus in [7] to improve the shifting quality. In [8], the performances of multi-speed AMT and fixed ratio gearbox in an electric vehicle were compared and the results revealed that the overall energy consumption has been decreased by $5-12 \%$ with a multi-speed AMT depending on the driving cycle used. In [9], the necessity of using a multispeed AMT for pure electric vehicles has been discussed. The results showed that a three speed transmission with optimized gear ratios reduced the energy consumption by $9.3 \%$ compared with an electric vehicle with single-speed transmission.

On the other hand, shifting jerk and power interruption problems are still the challenges of AMT that should be handled carefully [10-11]. In order to overcome these problems, an electric driven AMT was proposed in [12] for a parallel plug-in hybrid electric vehicle (PHEV) such that the engine and traction electric motor were positioned on the same shaft with an automatic clutch and an electric motor was integrated to the AMT for shifting purpose. Gear shifting was realized by adjusting the speed of the electric motor without using a synchronizer. Dual clutch AMT [13-14] has been also used to improve the shifting quality. The shift shock can be reduced by controlling the speed of the clutch [15] or the clutch itself can be eliminated by coordinately controlling the speed and torque of the engine and electric motor in hybrid electric vehicles [16-17]. In [18], a shaft torque observer has been used to determine the optimal gear upshift points where the torque interruption time is short and the shift jerk is small. In the literature, there has been also some optimization based gear shifting strategies in order to improve the shifting quality and vehicle performance. In [19], the gearshift sequences have been determined by dynamic programming approach with a priori knowledge of the road trajectory. Genetic algorithm has been also used in gear shifting strategy in order to reduce the fuel consumption and emissions [20].

In this paper, to overcome the above mentioned problems, a new six-speed robotized gearbox with a gear shift control strategy has been proposed for an electric city bus. Gear shifting mechanism has been created by using pneumatic actuators and control valves. Electric motor is coupled to the gearbox without clutch and synchronizer. A smooth gear engagement has been achieved by synchronizing the speed of the electric motor with the speed of the gearbox internals and precise torque control of the electric motor during shifting process. Experimental results on a prototype electric bus showed that the shifting quality is quite satisfactory and electric motor is operated within rated torque limits in the majority of time during driving cycle that results in more efficient operation of the electric motor than in case of using a fixed ratio gearbox.

\section{The structure of the proposed robotized gearbox}

Fig. 1 shows the general layout of the developed powertrain system in the electric bus.

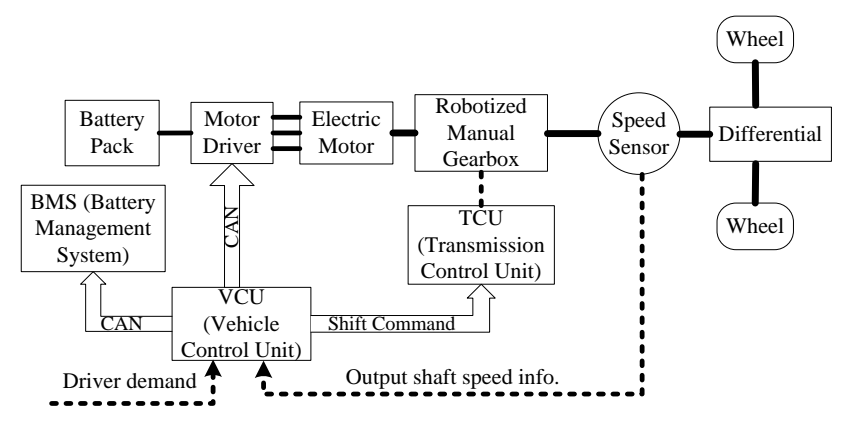

Fig. 1 Powertrain layout of the battery electric bus

As can be seen from Fig. 1, vehicle control unit (VCU) communicates with battery management system 
(BMS) and transmission control unit (TCU) via controller area network (CAN). VCU takes driver demand from accelerator/brake pedals, output shaft speed from speed sensor and actual gear information from TCU over CAN. VCU follows a speed based gear shifting strategy in which the aim is to keep the transmission's output shaft speed within a certain range. Upshift and downshift events are determined based on a two dimensional shifting map which is created from the actual gear value and driver demanded torque as illustrated in Fig. 2.

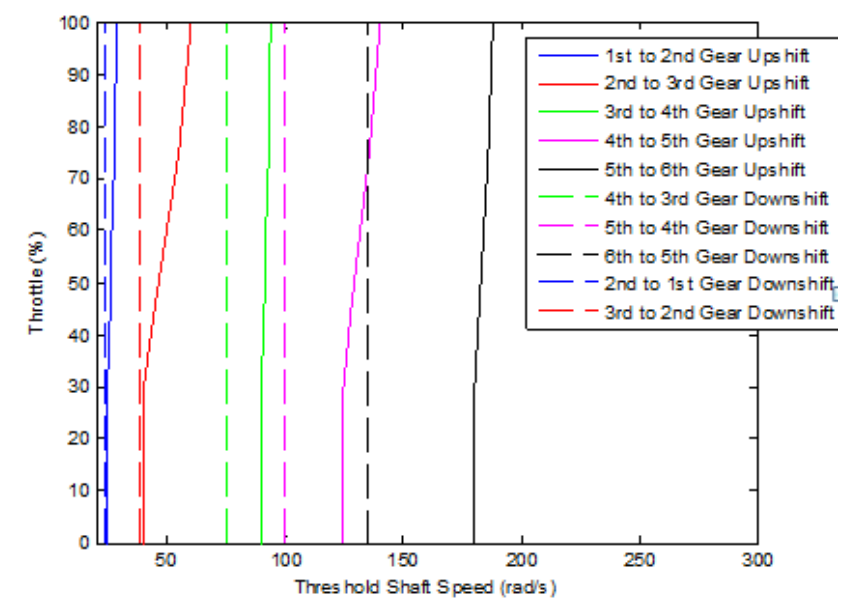

Fig. 2 Gear shifting map

The outputs of the map are threshold values for transmission's output shaft speed such that if the threshold value is higher than the actual shaft speed, a lower gear is requested and if the threshold value is lower than the actual shaft speed, a higher gear is requested. There is hysteresis range between each upshift and downshift sequence in order to avoid frequent switching between gears.

VCU transmits calculated shift commands to TCU and the required torque/speed reference values to motor driver over CAN. Electric motor is connected to the gearbox without clutch and synchronizer as shown in Fig. 3. Shifting is performed inside the transmission by using sliding sleeves.

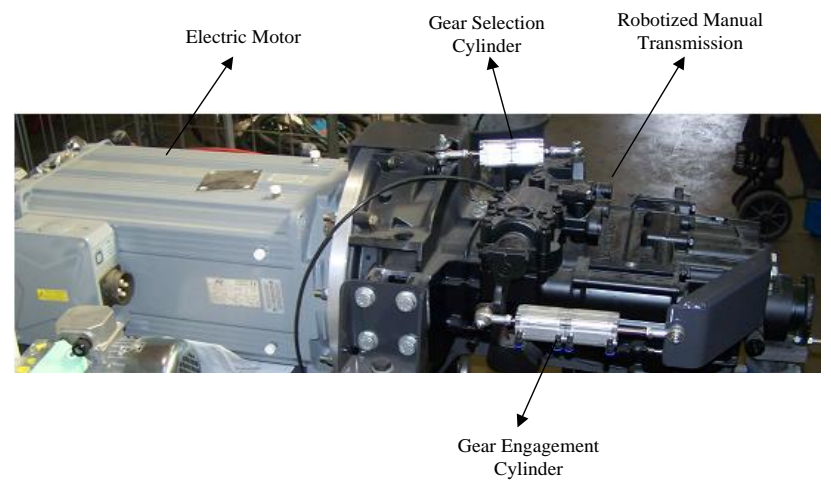

Fig. 3 Powertrain structure

Fig. 4 shows the schematic of the proposed gearbox control system. The system consists of a six speed robotized manual transmission, a gear engagement cylinder with two reed-type position sensors, a gear selection cylinder, an air compressor for pressurized air (i.e. 10 bar) being stored in the air tank, a regulator to lower the pressure to 4.5 bar and four double solenoid air control valves (i.e. valves
1-4). In the proposed gearbox structure, pneumatic system has been considered instead of hydraulic one due to its high compressibility and maintainability as well as low weight and cost.

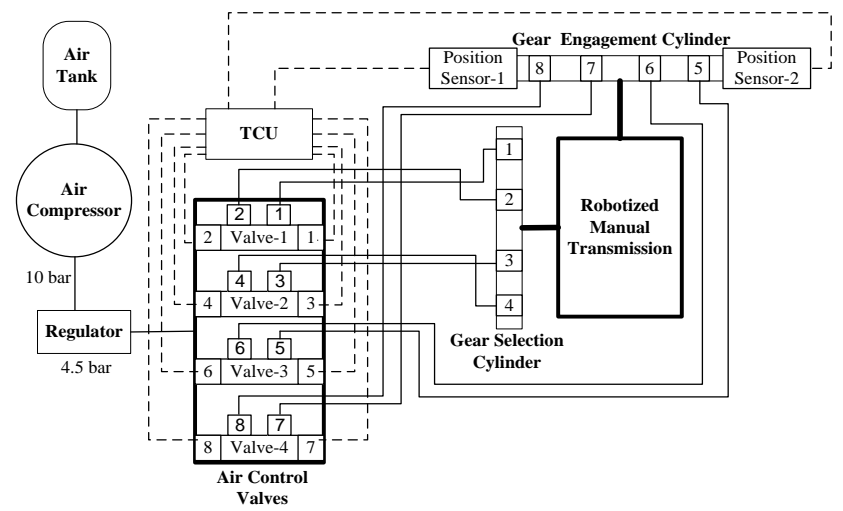

Fig. 4 Schematic of gearbox control system

As shown in Fig. 4, each valve has two solenoids and each cylinder has four air ports. Thus, TCU controls eight solenoid valves according to the shift command. Position sensors located on the gear engagement cylinder indicate if the requested gear is engaged successfully or not (i.e. " 1 " if successful, " 0 " otherwise). Fig. 5 and Fig. 6 show the realization of the gearbox control system and the installation of the position sensors on the gear engagement cylinder in the vehicle, respectively.

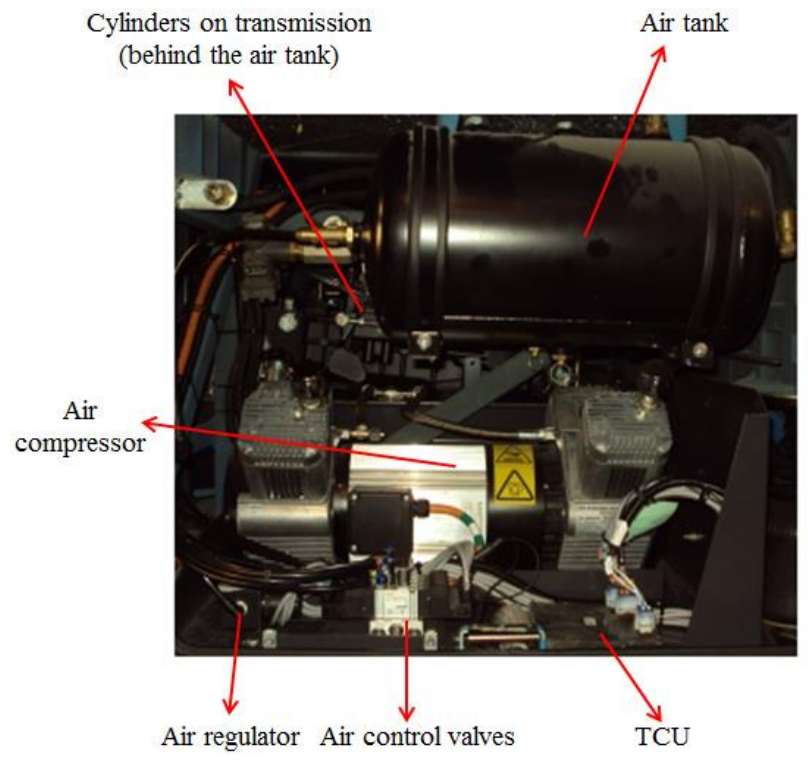

Fig. 5 Gearbox control system installed in the vehicle

TCU controls the air control valves and manages the air that flows into the pneumatic cylinders. The output of the air control valves is regulated by air regulator to reduce the air pressure from 10 bars to 4.5 bars to keep the air pressure in an adequate level for cylinders.

Position sensors are located on each side of the gear engagement cylinder as shown in Fig. 6. The correct positioning of the sensors is determined during installation by trial and error until the correct signal is achieved for each gear change. 


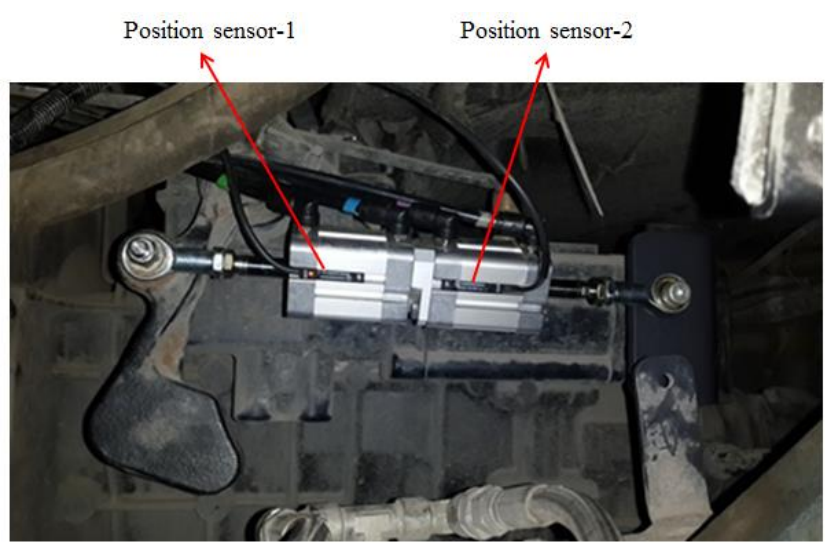

Fig. 6 Position sensors on gear engagement cylinder

\section{Gearshift control strategy}

The flow chart of the gear shifting process is shown in Fig. 7.

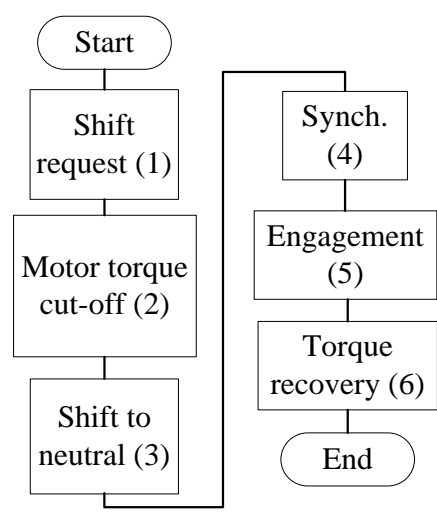

Fig. 7 Gear shifting control process

As shown in Fig. 7, the gear engagement process is completed in six steps as described below.

Shift request phase. In this step, VCU sends the upshift or downshift command to TCU over CAN.

Motor torque cut-off phase. TCU requests electric motor to cut-off the torque in order to avoid damaging the gear teeth and to reduce the shift jerk before engagement.

Shift to neutral. Gear is shifted to neutral position to allow the pneumatic actuators to select the target gear.

Synchronization phase. VCU sends target speed value to motor driver over CAN such that the speed of the electric motor is synchronized with output shaft speed. When the speed difference is in acceptable range, engagement process is executed.

Engagement phase. TCU operates air control valves to engage the requested gear.

Torque recovery phase. After engagement phase, electric motor torque is restored to the driver's demanded torque.

In this study, the following main shifting quality parameters are evaluated [21].

The gear shifting time. The time between the start and end of shifting process. It includes the time $t_{1}$ of decreasing the torque of electric motor to zero, the time $t_{2}$ of disengaging the gear to neutral, the time $t_{3}$ of regulating the speed of electric motor, the time $t_{4}$ of shifting to the requested gear and the time $t_{5}$ of torque recovery. The total shift time can be expressed as:

$$
t_{\text {shift }}=t_{1}(t)+t_{2}(t)+t_{3}(t)+t_{4}(t)+t_{5}(t) .
$$

The gear shifting jerk. Jerk is the derivative of longitudinal acceleration which reflects the oscillation of driving torque as:

$$
j=\frac{d a(t)}{d(t)}=\frac{r_{w}}{i_{0} i_{g}} \frac{d^{2} w_{m}}{d t^{2}},
$$

where $a$ is longitudinal acceleration, $i_{0}$ is differential ratio, $i_{g}$ is actual gear ratio, $r_{w}$ is wheel radius and $w_{m}$ is electric motor speed in $\mathrm{rad} / \mathrm{s}$.

Table 1 shows the control logic of solenoid valves for each gear transition. In shifting process, the gear is shifted to neutral first and then engaged to target gear.

Table 1

Control logic of solenoid valves

$\begin{array}{lllllllll}\text { Gear } & \text { V1 } & \text { V2 } & \text { V3 } & \text { V4 } & \text { V5 } & \text { V6 } & \text { V7 } & \text { V8 }\end{array}$

\begin{tabular}{ccccccccc}
\hline $\mathrm{N}$ & 0 & 1 & 0 & 0 & 0 & 0 & 1 & 0 \\
\hline 1 & 0 & 1 & 1 & 0 & 1 & 0 & 0 & 1 \\
\hline 2 & 0 & 1 & 1 & 0 & 0 & 1 & 1 & 0 \\
\hline 3 & 0 & 1 & 0 & 1 & 1 & 0 & 0 & 1 \\
\hline 4 & 0 & 1 & 0 & 1 & 0 & 1 & 1 & 0 \\
\hline 5 & 1 & 0 & 0 & 1 & 1 & 0 & 0 & 1 \\
\hline 6 & 1 & 0 & 0 & 1 & 0 & 1 & 1 & 0 \\
\hline$R$ & 1 & 0 & 0 & 0 & 0 & 0 & 1 & 0 \\
\hline
\end{tabular}

\section{Experimental study}

In this section, 2 case studies have been conducted. The objective of the first case study is to compare the shifting quality of the proposed gearbox system with an alternative one already applied to the electric bus in [22]. In the second case study, the efficiency of the proposed gearbox system has been investigated by making several comparisons with the fixed ratio gearbox under city driving cycle conditions. For example, operating torque and efficiency of the electric motor and energy consumption of the battery system has been studied for each gearbox solution.

The robotized gearbox was applied to a 9 meter prototype electric bus as shown in Fig. 8 to see the performance of gear shifting strategy on real road conditions. Table 2 shows the real vehicle and drivetrain parameters.

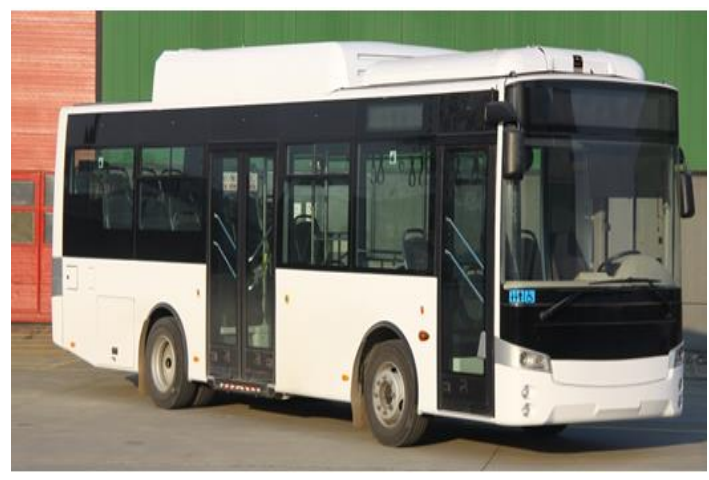

Fig. 8 The prototype test vehicle 
Vehicle test parameters

\begin{tabular}{lll}
\hline & Parameters & Value \\
\hline & GVW & $13500 \mathrm{~kg}$ \\
& Wheel rolling radius & 0.46 \\
& Aerodynamic drag coeffi- & 0.61 \\
Vehicle & cient & \\
Dynamics & Frontal area & $6.8 \mathrm{~m} 2$ \\
& Differential ratio & 5.83 \\
& Transmission ratio & {$[6.583 .62 .13$} \\
& (6 speed) & $1.3910 .78]$ \\
\hline Electric & Peak power & $118 \mathrm{~kW}$ \\
Motor & Maximum torque & $550 \mathrm{Nm}$ \\
\hline \multirow{2}{*}{ Battery } & Capacity & $276 \mathrm{Ah}$ \\
& Rated voltage & $615 \mathrm{~V}$ \\
\hline
\end{tabular}

\section{Case Study-1}

In this case study, the full-loaded vehicle was accelerated from standstill to the maximum speed on a flat road as shown in Fig. 9.

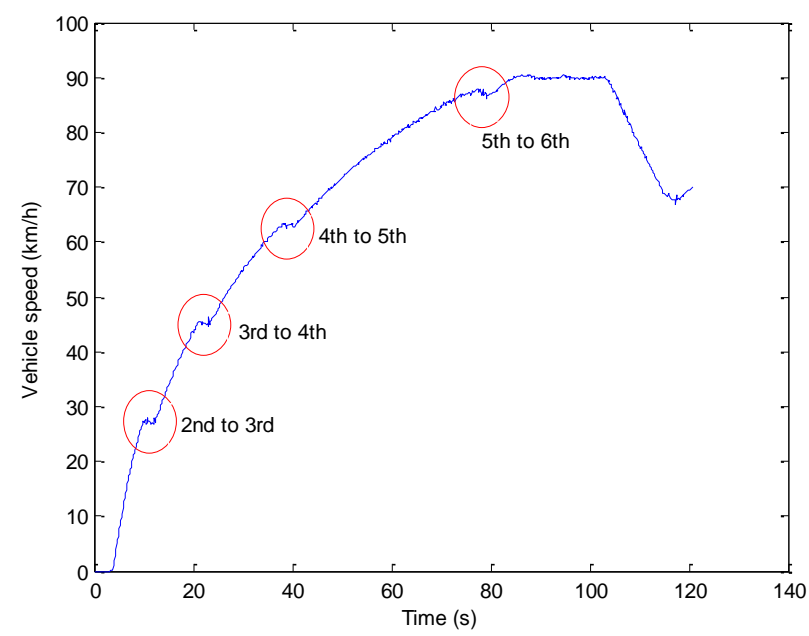

Fig. 9 Vehicle speed during shifting process

The vehicle starts from 2-nd gear and shifts to 6-th gear until the speed hits $90 \mathrm{~km} / \mathrm{h}$. Test data were recorded using a data logger and CANalyzer tool and then analyzed in MATLAB program.

Fig. 10 shows the test results of the speed and torque responses of the electric motor and the shift jerk during gear changing from 2-nd gear to 3-rd gear.

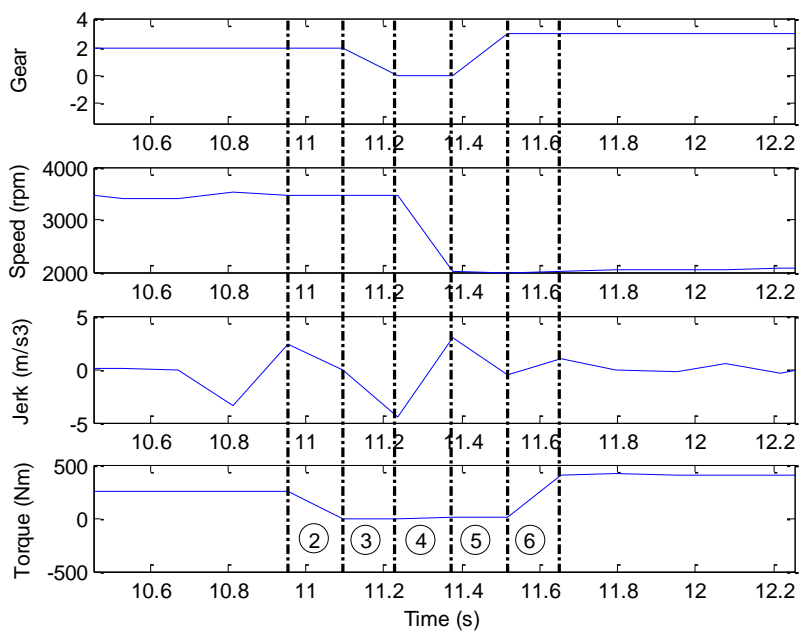

Fig. 10 Test results of shifting sequences
Gear changing process starts with shift request transmitted from VCU to the TCU. The time interval of each step in Fig. 7 was marked with a number on Fig. 10 in order to evaluate the performance of the gear shifting control strategy. Fig. 11 shows the speed variations of the electric motor and the output shaft during shifting process.

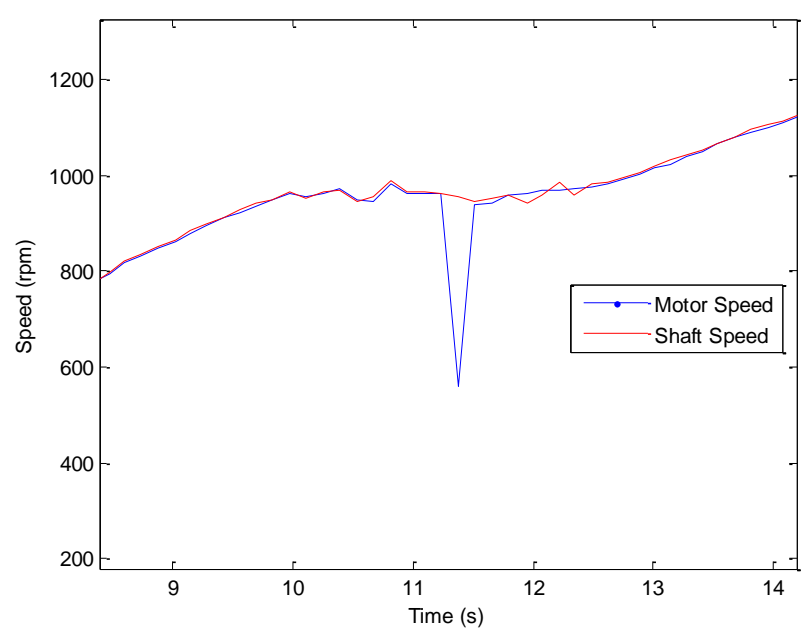

Fig. 11 Speed variations of the electric motor and output shaft

The shifting quality of the robotized gearbox has been compared with that of an existing pure electric bus equipped with a clutchless AMT [22]. Table 3 shows the comparative test results in terms of shift speed.

Table 3

Comparative test results

\begin{tabular}{cccc}
\hline No. & Step & $\begin{array}{c}\text { Robotized } \\
\text { Gearbox } \\
\text { Time (ms) }\end{array}$ & $\begin{array}{c}\text { AMT [22] } \\
\text { Time (ms) }\end{array}$ \\
\hline 2 & Torque cut-off & 120 & 60 \\
\hline 3 & Shift to neutral & 140 & 180 \\
\hline 4 & Speed synch. & 170 & 420 \\
\hline 5 & Engagement & 150 & 160 \\
\hline 6 & Torque recovery & 140 & 130 \\
\hline
\end{tabular}

As can be seen from Table 3, the total shifting time of the robotized gearbox is $0.72 \mathrm{~s}$ which is shorter than that of AMT [23] which is $0.95 \mathrm{~s}$. This difference is mainly due to the time needed for adjusting the speed of the electric motor in synchronization phase. It shows that the speed control of the electric motor has great impact on shifting quality. The time of engagement and disengagement also affects the shifting speed and it is mainly dependent on the speed of the actuators. Torque recovery time is dependent on the driver torque demand. As the speed fluctuation is small and the speed and torque of the electric motor is well controlled, the gear change is smooth and the shift jerk is around $\pm 4 \mathrm{~m} / \mathrm{s}^{3}$ which is quite satisfactory.

\section{Case Study-2}

In this case study, the vehicle has been equipped first with the proposed gearbox system and then with a fixed ratio gearbox for comparison purpose. The vehicle has been tested on a chassis dynamometer to compare the test results. The dyno environment has been built as shown in Fig. 12 and the tests have been performed as recommended in SAE J-2711 [23]. 


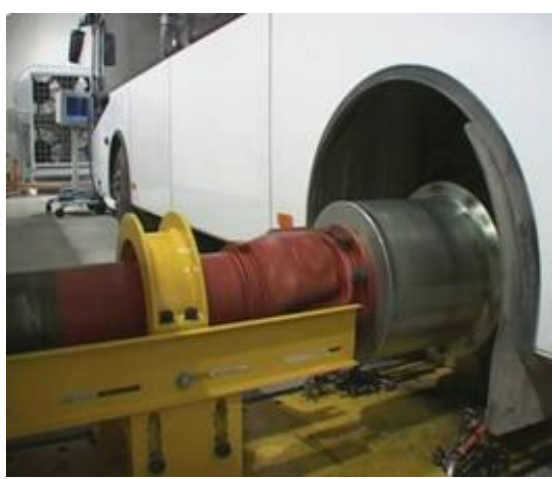

Fig. 12 Test vehicle on chassis dynamometer

The vehicle speed has been controlled automatically to follow the EPA UDDS (Urban Dynamometer Driving Schedule) driving cycle that has been widely used for heavy-duty vehicles as shown in Fig. 13.

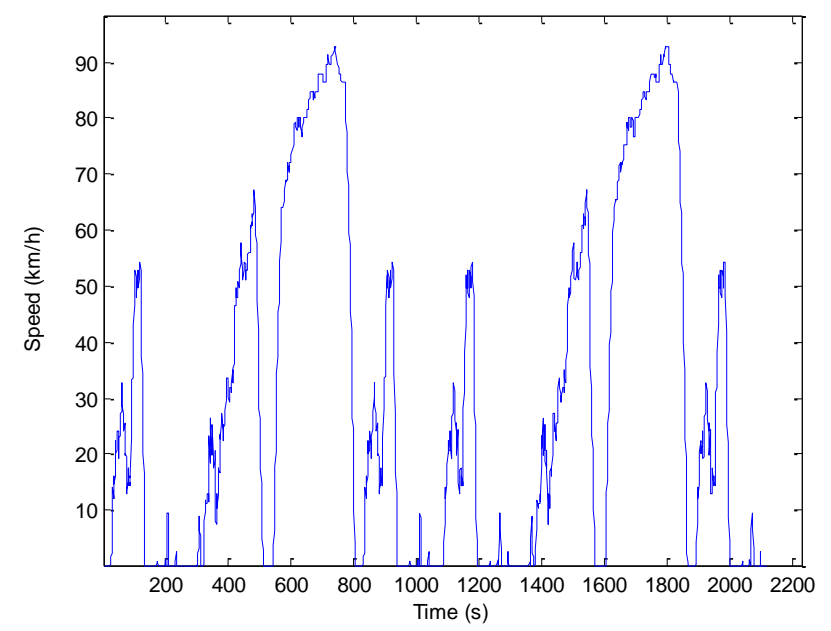

Fig. 13 UDDS driving cycle

The basic parameters of the UDDS cycle are as follows; the duration is $1060 \mathrm{sec}$., the average speed is $30.4 \mathrm{~km} / \mathrm{h}$, the maximum speed is $93.3 \mathrm{~km} / \mathrm{h}$ and the distance is $8.9 \mathrm{~km}$. In this case study, two successive cycles were used to simulate an average city bus trip length of $18 \mathrm{~km}$.

Under this driving cycle conditions, the operating points (i.e. torque and speed) of the electric motor have been plotted for both gearbox solutions.

Fig. 14 shows the torque and speed values of the electric motor obtained for the proposed gearbox system. In Fig. 14, negative torque values corresponding to the regenerative braking events during deceleration indicate that the electric motor has been operated in generator mode. It is seen that operating points are within the maximum torque range of the electric motor (i.e. $550 \mathrm{Nm}$ ). As a result, the electric motor is operated in the most efficient region of its efficiency map.

In a similar way, the performance of the fixed ratio gearbox has been investigated for comparison purpose under same conditions. The bus has been equipped with a fixed ratio gearbox with a ratio of 1.22 . This ratio has been chosen to meet the acceleration and maximum speed (i.e. $90 \mathrm{~km} / \mathrm{h}$ ) requirement of the driving cycle. In this case, the torque and speed values of the electric motor obtained for UDDS driving cycle for the fixed ratio gearbox has been plotted in Fig. 15.

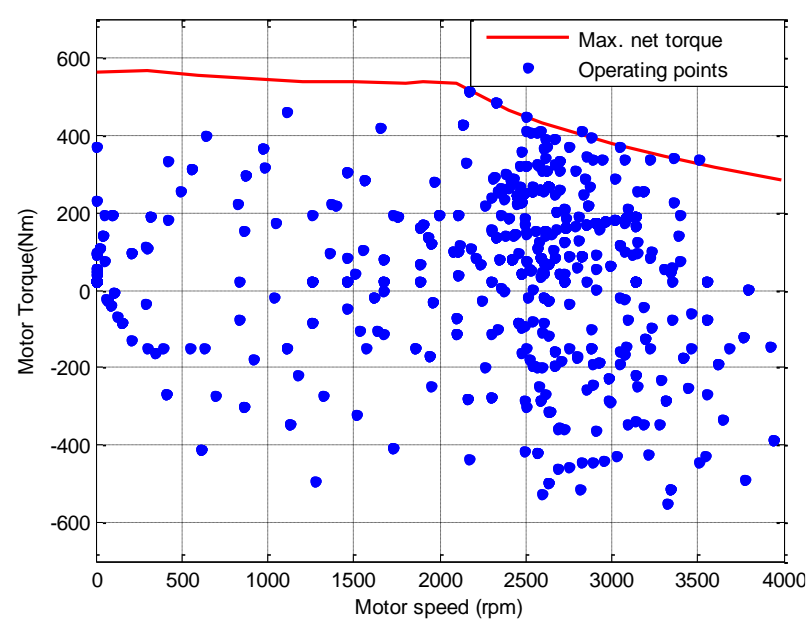

Fig. 14 Operating points of electric motor for the proposed gearbox system

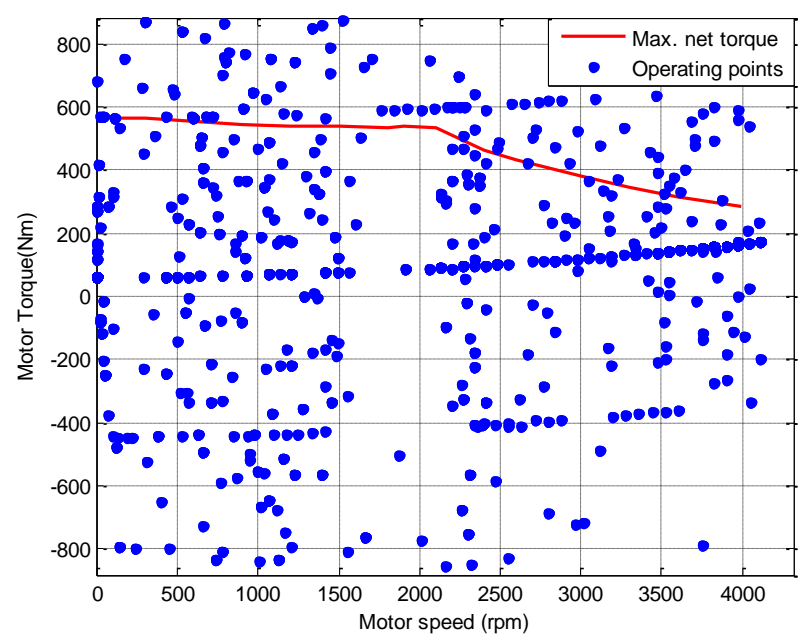

Fig. 15 Operating points of electric motor for the fixed ratio gearbox

As can be seen from Fig. 15, the operating torque values are above the maximum torque curve at some points where high drive torque is needed at the wheels. The maximum motor torque (i.e. $820 \mathrm{Nm}$ ) realized is $50 \%$ higher than what is obtained in the proposed gearbox system (i.e. $550 \mathrm{Nm}$ ). This causes the electric motor to draw a higher current from the batteries that results in over heating problem.

Furthermore, this situation increases the energy consumption of the batteries during over torque operation. The battery energy consumption during driving cycle has been calculated for the proposed gearbox system and the fixed ratio gearbox, respectively. Table 4 shows the comparative test results for UDDS driving cycle.

Table 4

Energy consumption test results

\begin{tabular}{ccc}
\hline $\begin{array}{c}\text { UDDS } \\
\text { Cycle }\end{array}$ & $\begin{array}{c}\text { Proposed } \\
\text { gearbox }\end{array}$ & $\begin{array}{c}\text { Fixed ratio } \\
\text { gearbox }\end{array}$ \\
\hline $\begin{array}{c}\text { Energy } \\
\text { Consumption, kWh }\end{array}$ & 3.7 & 3.92 \\
\hline
\end{tabular}

From Table 4, it is seen that the energy consumed from the battery has been reduced by $\% 6$ with the proposed gearbox unit for UDDS driving cycle. This energy saving 
can be significant when considering that the city buses run whole day.

\section{Conclusions}

This paper addressed the issue of poor shifting quality of the conventional AMTs and investigated the effect of using AMT on the energy consumption and electric motor performance. For this purpose, a robotized gearbox system without clutch and synchronizer is successfully applied to the battery electric bus as a new design. The comparative experimental results of two case studies showed that:

1. The proposed system with proper gearshift control strategy provides improvements in shift speed and shift comfort such that the shift time is $0.72 \mathrm{~s}$ and the shift jerk is only $\pm 4 \mathrm{~m} / \mathrm{s}^{3}$.

2. The energy drawn from the battery is $3.7 \mathrm{kWh}$ for the proposed system whilst it is $3.92 \mathrm{kWh}$ for the fixed ratio gearbox system for a typical heavy-duty driving cycle. Thus, with the proposed system, $6 \%$ energy saving has been achieved.

3. The maximum operating torque of the electric motor has been realized as $550 \mathrm{Nm}$ with the proposed system which is $50 \%$ less than those obtained with fixed ratio gearbox system (i.e. $820 \mathrm{Nm}$ ). Thus, the electric motor has been operated much more efficiently with the proposed system.

Overall, the proposed 6 speeds gearbox system benefits from energy saving advantage of AMT systems without compromising the driving comfort during shifting process in electric vehicles.

\section{References}

1. Yuan, Y.; Wu, G.; He, X.; Song, Y.; Zhang, X. 2012. Electric vehicle drivetrain development in China, International Symposium on Flexible Automation Conference.

http://dx.doi.org/10.1115/ISFA2012-7212.

2. Jansen, S.T.H.; van Boekel, J.J.P.; van Iersel, S.S.; Besselink, I.J.M.; Nijmeijer, H. 2013. Vehicle state estimator based regenerative braking implementation on an electric vehicle to improve lateral vehicle stability, Electric Vehicle Symposium and Exhibition, 1-12. http://dx.doi.org/10.1109/EVS.2013.6915034.

3. Bottiglione, F.; De Pinto, S.; Mantriota, G.; Sorniotti, A. 2014. Energy consumption of a battery electric vehicle with infinitely variable transmission, Energies 7: 8317-8337. http://dx.doi.org/10.3390/en7128317.

4. Montezari, M.; Pourbafarani, Z. 2012. Simultaneous design of the gear ratio and gearshift strategy for a parallel hybrid electric vehicle equipped with amt, Int. J. of Vehicle Design 58: 291-306.

https://doi.org/10.1504/IJVD.2012.047389.

5. Liang, C.; Qingnian, W.; Youde, L.; Zhimin, M. 1999. Study of the electronic control strategy for the power train of hybrid electric vehicle, Proceedings of the IEEE International Vehicle Electronics Conference. http://dx.doi.org/10.1109/IVEC.1999.830710.

6. Zhang, Z.S.; Xiao, H.J.; Yang, C.F.; Ling, L.; Wu, B.H. 2013. The synchronous control of automated man- ual transmission in three-gear electric bus, Applied Mechanics and Materials 419: 731-734.

http://dx.doi.org/10.4028/www.scien-

tific.net/AMM.419.731.

7. Ling, L.; Chen, Z.S.; Luo, Y.Y. 2012. Study on control process of automatic mechanical transmission system for pure electric bus, Applied Mechanics and Materials 220: 1795-1799.

http://dx.doi.org/10.4028/www.scien-

tific.net/AMM.220-223.1795.

8. Ren, Q.; Crolla, A.; Morris, A. 2009. Effect of transmission design on electric vehicle (EV) performance, IEEE Vehicle Power and Propulsion Conference. http://dx.doi.org/10.1109/VPPC.2009.5289707.

9. Zhang, Z.; Zuo, C.; Hao, W.; Zuo, Y.; Zhao, X.L.; Zhang, M.; Chen, Z.S.; Luo, Y.Y. 2013. Three-speed transmission system for purely electric vehicles, Int. Journal of Automotive Technology 14: 773-778. http://dx.doi.org/10.1007/s12239-013-0085-0.

10. Mashadi, B.; Kazemkhani, A.; Lakeh, R.B. 2007. An automatic gear-shifting strategy for manual transmissions, Proceedings of the Institution of Mechanical Engineers, Part I: Journal of Systems and Control Engineering 221: 757-768. http://dx.doi.org/10.1243/09596518JSCE253.

11. Ye, M.; Qin, D.T.; Liu, Z.J. 2009. Shift performance control for mild hybrid electric vehicle equipped with automatic manual transmission, Chinese Journal of Mechanical Engineering 45: 108-114. http://dx.doi.org/10.3901/JME.2009.05.108.

12. Yang, Y.; Wu, S. 2014. The research on gearshift control strategies of a plug-in parallel hybrid electric vehicle equipped with emt, Journal of Chemical and Pharmaceutical Research 6: 1647-1652.

13. Kulkarni, M.; Shim, T.; Zhang, Y. 2007. Shift dynamics and control of dual-clutch transmissions, Mechanism and Machine Theory 42: 168-182.

http://dx.doi.org/10.1016/j.mechmachtheory.2006.03.002.

14. Song, Z.; Guangqiang, Z.; Songlin, Z. 2010. Study on the energy management strategy of DTC-based seriesparallel PHEV, Computing, Control and Industrial Engineering (CCIE) Conference.

http://dx.doi.org/10.1109/CCIE.2010.14.

15. Cho, S.T.; Jeon, S.; Jo, H.S.; Lee, J.M.; Park, Y.I. 2001. A development of shift control algorithm for improving the shift characteristics of the automated manual transmission in the hybrid drivetrain, Int. J. of Vehicle Design 26: 469-495. http://dx.doi.org/10.1504/IJVD.2001.005219.

16. Petterson, M.; Nielsen, L. 2000. Gear shift by engine control, IEEE Trans. Control Syst. Technol. 8: 495-507. https://doi.org/10.1109/87.845880.

17. He, H.; Liu, Z.; Zhu, L.; Liu, X. 2012. Dynamic coordinated shifting control of automated mechanical transmissions without a clutch in a plug-in hybrid electric vehicle, Energies 5: 3094-3109. http://dx.doi.org/10.3390/en5083094.

18. Gao, B.; Lu, X.; Chen, H.; Lu, X.; Li, J. 2013. Dynamics and control of gear upshift in automated manual transmissions, Int. J. of Vehicle Design 63: 61-83. http://dx.doi.org/10.1504/IJVD.2013.055533. 
19. Jacobson, B.; Spickenreuther, M. 2003. Gearshift sequence optimisation for vehicles with automated nonpower shifting transmissions, Int. J. of Vehicle Design 32: 187-207. http://dx.doi.org/10.1504/IJVD.2003.003563.

20. Montezari, M.; Asadi, M. 2009. Optimisation of amt gear shifting strategy in hybrid electric vehicles, Int. J. of Vehicle Autonomous Systems 7: 1-17. http://dx.doi.org/10.1504/IJVAS.2009.027964.

21. Yu, H.L.; Xi, J.Q.; Zhang, F.Q.; Hu, Y.H. 2014. Research on gear shifting process without disengaging clutch for a parallel hybrid electric vehicle equipped with AMT, Mathematical Problems in Engineering 2014: 1-12. https://doi.org/10.1155/2014/671589.

22. Shaohua, S.; Yulong, L.; Cheng, Y.; Jietao, W. 2012. Analysis and control of shift process for AMT without synchronizer in battery electric bus, International Conference on Electronic and Mechanical Engineering and Information Technology. http://dx.doi.org/10.2991/emeit.2012.450.

23. SAE J-2711. 2002. Analysis and control of shift process for AMT without synchronizer in battery electric bus, Recommended practice for measuring fuel economy and emissions of hybrid-electric and conventional heavyduty vehicles, Technical paper.

\section{K. Gokce}

\section{PERFORMANCE EVALUATION OF A NEWLY DESIGNED ROBOTIZED GEARBOX FOR ELECTRIC CITY BUSES}

\section{S u m m a r y}

Automated manual transmissions (AMT) play an important role in reducing energy consumption in electric vehicles. However, a major concern that limits the usage of AMTs is their poor gear shifting quality that reduces the driving comfort. In this study, a new pneumatically driven robotized gearbox without clutch and synchronizer is introduced and a gear shifting control scheme is developed for an electric city bus. A six speed manual transmission has been robotized (automated) by using two pneumatic double acting cylinders, four three position double solenoid air control valves and a transmission control unit. The speeds of the electric motor and the output shaft of the gear mechanism are well synchronized during shifting process. Experimental study carried out on a prototype electric bus revealed that the new design improves the gear shifting quality such that the shift speed is quite fast and the shift jerk is within the acceptable. The performance of the proposed gearbox has been also compared with that of fixed ratio gearbox and the comparative test results showed that, thanks to the proposed gearbox system, the electric motor is operated efficiently within rated torque limits and the energy consumption is reduced to a large extent.

Keywords: electric bus, automated manual transmission, design, gearbox, control. 